\title{
How do unisex life care annuities embedded in a pay-as-you-go retirement system affect gender redistribution?
}

Complutense de Análisis Económico

\author{
Javier Pla-Porcel \\ Actuarial Department, SOS Seguros y Reaseguros, S.A., Madrid. (Spain)
}

\section{Manuel Ventura-Marco}

Department of Financial Economics and Actuarial Science, University of Valencia, Spain.

\section{Carlos Vidal-Meliá}

Department of Financial Economics and Actuarial Science, University of Valencia, Spain, and Instituto Complutense de Análisis Económico, Complutense University of Madrid, Spain.

\begin{abstract}
This paper aims to assess gender redistribution when using unisex conversion factors to compute the initial benefit of life care annuities (LCAs) embedded in a pay-as-you-go (PAYG) pension system. We use a method based on actuarial factors to disentangle the hidden redistribution of LCAs with graded benefits. The value of the actuarial factor relies on a multistate framework in which transitions are modeled from the initial health state to the absorbing state. According to our calculations for Australia and the US, the amount of gender redistribution is by no means irrelevant. In spite of the very different biometric data, the results are surprisingly similar for both countries. Risk equalization based on the "equal treatment" of men and women may not be fair, given that age, gender and health state are very significant risk factors in computing the initial benefit in a system covering retirement and long-term care.
\end{abstract}

Keywords Gender, Life Care Annuities, Long-Term Care Insurance, Multistate model, Redistribution, Retirement.

JEL Classification $\quad$ G22, H55, I13, J14, J26

\section{Working Paper no 1711}

\author{
March, 2017
}

UNIVERSIDAD

COMPLUTENSE

MADRID

ISSN: 2341-2356 


\section{How do unisex life care annuities embedded in a pay-as-you-go retirement system affect gender redistribution?*}

\section{Javier Pla-Porcel†, Manuel Ventura-Marco $¥$ and Carlos Vidal-Meliás}

$23 / 03 / 2017$

This paper aims to assess gender redistribution when using unisex conversion factors to compute the initial benefit of life care annuities (LCAs) embedded in a pay-as-you-go (PAYG) pension system. We use a method based on actuarial factors to disentangle the hidden redistribution of LCAs with graded benefits. The value of the actuarial factor relies on a multistate framework in which transitions are modeled from the initial health state to the absorbing state. According to our calculations for Australia and the US, the amount of gender redistribution is by no means irrelevant. In spite of the very different biometric data, the results are surprisingly similar for both countries. Risk equalization based on the "equal treatment" of men and women may not be fair, given that age, gender and health state are very significant risk factors in computing the initial benefit in a system covering retirement and long-term care.

JEL: G22, H55, I13, J14, J26

KEYWORDS: Gender, Life Care Annuities, Long-Term Care Insurance, Multistate model, Redistribution, Retirement.

\footnotetext{
* Manuel Ventura-Marco and Carlos Vidal-Meliá are grateful for the financial assistance received from the Spanish Ministry of the Economy and Competitiveness (Ministerio de Economía y Competitividad) project ECO201565826-P. They would also like to thank Peter Hall for his English support and Juan Manuel Pérez-Salamero González for his help in obtaining data for performing the numerical example. Any errors are entirely our own.

${ }^{\dagger}$ Actuarial Department, SOS Seguros y Reaseguros, S.A., Madrid. (Spain). (e-mail: javier.pla@internationalsos.com).

‡ Department of Financial Economics and Actuarial Science, University of Valencia, Spain. (e-mail: manuel.ventura@uv.es).

$\S$ Department of Financial Economics and Actuarial Science, University of Valencia, Spain, and Instituto Complutense de Análisis Económico, Complutense University of Madrid, Spain. (e-mail: carlos.vidal@uv.es). (Corresponding author)
} 


\section{1.-Introduction}

It has long been known that the cost of providing products such as motor insurance, private medical insurance, life insurance, pension annuities and life-care annuities (LCAs) varies greatly between men and women. According to Oxera (2011a, 2011b, 2011c), gender is the second most important risk-rating factor (after age) for some insurance products, and until December 212012 gender-specific premium differentiation was allowed in most European Union (EU) member states ${ }^{1}$ for risks that are strongly linked to gender ${ }^{2}$. Company pension schemes are not formally affected by the ruling.

This authors of this paper are very interested in the idea of linking retirement and long-term care (LTC) coverage from a social insurance perspective. Chen (1994, 2001, 2003), Pitacco (2002), Forder and Fernandez (2011), Costa-Font et al. (2014), Pla-Porcel et al. (2016a, 2016b) and Tanaka (2016) discuss this idea but with very different approaches, the last three of these papers being the most detailed. The proposal to convert retirement benefit into an LCA with graded benefits using a pre-existing public pay-as-you-go (PAYG) pension scheme is particularly attractive as a means of extending LTC coverage to retirement pensioners. For this reason we focus on LCAs, also known as life care pensions.

Compulsory public insurance delivered through social security systems is provided on a community-rated basis, with all affiliates being subject to the same rules for calculating contributions and benefits regardless of risk profiles ${ }^{3}$. It has long been recognized that the use of gender-neutral annuities in PAYG pension systems simply redistributes from males to females, mainly due to the fact that women outlive men. There are other channels of redistribution in PAYG pension systems, the most important being along educational lines (from the less welleducated to the highly educated) and between diverse lifetime-earning quintiles (from the poor to the rich) ${ }^{4}$. Nevertheless, in the funded part of some Latin-American multi-pillar pension systems (Mesa-Lago \& Bertranou, 2016), gender-specific rates are used to calculate benefits.

Looking to the future, it is expected that redistribution by sex could decrease given that gender differences in mortality will probably narrow in the decades to come. For England and Wales, Mayhew and Smith (2014) found a well-entrenched trend with life expectancy for males improving more quickly than for females over the most recent periods. They also analyzed other countries. In Japan, for example, they found that the gender difference in life expectancy is diverging, while in France convergence is progressing but at a much slower pace. In Sweden, by contrast, convergence is projected to occur earlier than in England and Wales.

The main argument in favour of community rating is that it tends to equalize the monthly benefits and thus the standard of living for both men and women. It is argued that the use of gender-specific mortality tables in the calculation of annuities is unfair because it ignores women's disadvantageous position in the labor market and worsens their situations, since women have greater life expectancy (Elveren, 2008; Bonnet \& Hourriez, 2012).

\footnotetext{
${ }^{1}$ According to Samuel (2014), apart from Massachusetts and Montana in the USA, this ruling is only a European issue as a result of Directive 2004/113/EC application (EC, 2011, European Court of Justice, 2011). By and large, the insurance industry's view of the ruling is extremely negative. Previously, Directive 79/7/EEC lay down the progressive implementation of the gender equality principle in matters of social security.

${ }^{2}$ The debate about equal treatment for men and women has a long tradition in Europe and is a fundamental principle of the European Union. The possible consequences for the insurance industry of the new regulation on gender equality in the EU are discussed in the papers by Schmeiser et al. (2014) and Aseervatham et al. (2016).

3 The question of systems covering survivor benefits by means of joint survivor annuities lies outside the scope of this article.

4 This subject has very complex implications and, for the particular cases of Italy, France, the US, Sweden and the UK, interested readers can consult the papers by Caselli et al. (2003), James et al. (2003), Ståhlberg et al. (2006), Barnay (2007), Whitehouse \& Zaidi (2008), Finkelstein et al. (2009), James (2012), Mazaferro et al. (2012), Gustman et al. (2013) and Aubert et al. (2013), to name just a few.
} 
From an ethical point of view (Thiery \& Van Schoubroeck, 2006), setting the initial benefit on the basis of factors over which an individual has little or no control, as in the case of gender, is considered unfair by most people. Conversely, gender differences in morbidity and mortality are well-documented in the more developed countries (Case \& Paxson, 2005; Luy \& Minagawav, 2014) and the so-called "gender and health paradox", which considers women's longevity advantage to be a major contributor to their health disadvantage, is today a valid issue. Along the same lines, Helwig (2014) pointed out that females have significantly higher morbidity than males, and therefore there are actuarial arguments for using gender-specific rates.

Apart from the data analyzed later in the numerical example, we look at the cases of two countries, the first being Australia and the other the US. Fong et al. (2017) analyze 30 years of historical mortality data for Australia in order to examine cohort and gender differences in health-state distributions among older adults. They find that older females undergo a faster rate of health deterioration than their male counterparts, causing them to move more quickly into worse states of health. Health states are also more heterogeneous among women than men.

Fong et al. (2015) also analyze a sample of older adults in the US aged between 50 and 100 at baseline in 1998. Their study provides new evidence on how morbidity-mortality transition rates vary by age and gender. They confirm that the rates of becoming LTC-disabled are significantly higher for women than men. Men and women also have different age patterns of recovery; whereas males face a recovery rate that decreases with age, females actually experience increasing chances of recovery up to about age 65 , after which the reverse is true.

From the insurance industry's point of view (Schmeiser et al., 2014), the actuarial calculation of risk differentiation in pricing is based on the principle of equivalence, which is estimated to exist when the present values of premiums and benefits are equal. The use of gender in assessing insurance risk is justified when it is endorsed by actuarial and statistical data. This approach minimizes cross-subsidization (redistribution) in the portfolio (pension system). For Ornelas et al. (2014), actuarial modeling is necessary even when regulatory circumstances impose rules on the use of risk factors such as gender for setting premium rates. Finally, Sass and Seifried (2014) analyze the impact of mandatory unisex tariffs on premium and insurance demand in both competitive and monopolistic market scenarios, showing that unisex tariffs may cause market distortions that significantly reduce overall social welfare.

This paper aims to assess gender redistribution when using unisex conversion factors ${ }^{5}$ to compute the initial benefit of life care annuities (LCAs) embedded in a pay-as-you-go (PAYG) pension system. According to our calculations based on accurate actuarial data from two developed countries (Australia and the US), the amount of gender redistribution is by no means irrelevant. Despite the very different biometric data, the results are surprisingly similar for both systems. On average, for a given structure of uplifts, the use of a gender-neutral actuarial factor to compute the initial benefit for females would increase the amount awarded by $12.94 \%$ (US) and $13.32 \%$ (Australia) respectively in the combined scheme. For males it would mean a reduction of between $9.48 \%$ (US) and $10.08 \%$ (Australia) in the initial payment if gender-neutral rates were used. As far as we know, this paper contributes to filling a gap in the literature because this issue has not been explored in detail in the case of a combined pension system covering retirement and LTC.

The paper proceeds as follows. After this introduction, Section 2 presents the methodology for valuing the gender redistribution in LCAs with graded benefits, which relies on a comparison of annuity factors. This shows how ex-ante systematic differences in mortality and morbidity affect the expected lifetime value of the initial LCA. To compute the conversion factors we use a

\footnotetext{
${ }^{5}$ In this paper the terms actuarial factor (rate), conversion factor (rate), annuity factor (rate) or simply annuity (rate) are considered to be synonyms and can be used interchangeably.
} 
multistate framework in which transitions are modeled from the initial state (healthy or at a given level of dependence) to the absorbing death state. Section 3 shows the results obtained for two numerical examples representative of the methodology seen in the previous section. It is divided into two parts: (a) the numerical outcomes for Australia resulting from using data from Hariyanto et al. (2014a, 2014b), and (b) the numerical results for the US using data obtained from Robinson's (1996) care transition model (CTM). In both parts we also look at what might happen if the annuitant's initial heath state is not able when they become entitled to benefits. The paper ends with some concluding comments, future research proposals and three appendices. The first of these explores three alternatives for building the unisex actuarial factor; the second provides detailed information on gender life expectancy in years at several ages and the percentage of total life expectancy likely to be spent in each of the states for the two sets of biometric assumptions used in the numerical example; and the third contains detailed results of gender redistribution by age and health state as well as other indicators.

\section{2.-The model for valuing gender redistribution in LCAs with graded benefits.}

Publicly-run LTC and private insurance schemes generally recognize several degrees of dependence. People are categorized into various levels depending on their inability to perform a given number of basic activities of daily living (ADLs, activities in which people engage on a dayto-day basis) ${ }^{6}$ and instrumental activities of daily living (IADLs, activities related to independent living which are valuable for evaluating people with early-stage illness, both to assess the level of the illness and to determine the person's ability to care for themselves) ${ }^{7}$. This classification has a direct effect on the amount of benefit paid.

An LCA with degree-related benefits is a lifetime annuity in which the LTC benefit is defined in terms of an uplift with respect to the basic amount, i.e. the initial retirement benefit in our proposal $^{8}$. In return for the payment of periodic contributions collected over time, the LCA provides a stream of fixed-income payments for the lifetime of the annuitant. It also provides an extra stream of payments if the annuitant requires LTC, and this amount depends on the policyholder's degree of dependence.

In line with the above, our model for valuing LCAs with $n$ graded benefits is based on the proposals first put forward by Pla-Porcel et al. (2016b). They take into account a model with $n$ levels of dependence, with level 1 being the least severe and level $n$ the most. Together with active $(a-$ able $)$ and death $(e$ - end), these states make up the space state for each age (i.e. each group). The health dynamics of the annuitant rely on the reversible illness-death model, in which transitions are modeled from the initial (healthy or disability) state to the absorbing death state.

In this type of LCA the LTC benefit is defined in terms of an uplift with respect to the basic payment, $b$. This initial payment $b$ is paid out from retirement onwards and is replaced by the LTC annuity benefit, $b \cdot\left(1+\xi_{a j}\right), j \in\{1,2, \cdots, n\}$, in the case of a successful LTC claim. When the recovery assumption is admitted, the amount of the annuity will have to be reduced if the individual makes the transition to a better health state.

In this LCA it is assumed that benefits are payable yearly in advance. Becoming an LTC recipient means that the amount of benefit is automatically increased by a certain percentage, $\xi$, to help pay for care services, i.e. those dependent on care will obtain additional cash to hire the necessary services as they see fit.

\footnotetext{
6 These are everyday personal care activities that are fundamental to caring for oneself and maintaining independence. They include bathing, dressing, grooming, mouth care, toileting, transferring bed/chair, walking, climbing stairs and eating.

${ }^{7}$ These include cooking, cleaning, doing laundry, shopping, using the telephone, accessing means of transport, taking medicines and managing money.

${ }^{8}$ On this subject see the papers/chapters by Haberman \& Pitacco (1999), Spillman et al. (2003), Warshawsky (2012) and Pitacco (2014).
} 
The key element for setting the initial benefit is the actuarial factor $\left(A F_{\left(x_{e}, g\right)}^{L C A(a, n)}\right)$. Generally speaking, this is the present value of a pension of an initial amount of 1 monetary unit from the age the pension is awarded until the death of the pensioner. In the case of a life care pension the amount paid depends on the annuitant's degree of dependence. This factor can be different depending on the gender $(g)$ of the annuitant: male $(m)$ or female $(f)$. We can also calculate a unisex $(u)$ factor (see Appendix 1). If the benefits corresponding to each of the individual's possible states are $b^{a}=1$ for $a, b^{d_{1}}=\left(1+\xi_{a 1}\right)$ for $d_{1}, b^{d_{2}}=\left(1+\xi_{a 2}\right)$ for $d_{2}$, and $\ldots \ldots \ldots, b^{d_{n}}=\left(1+\xi_{\text {an }}\right)$ for $d_{n}$, then:

$$
A F_{\left(x_{e}, g\right)}^{L C A(a, n)}=\ddot{a}_{\left(x_{e}, g\right)}^{a \alpha}+\sum_{j=1}^{n} \xi_{a j} A_{\left(x_{e}, g\right)}^{a d_{j} \alpha}
$$

where,

$\ddot{a}_{\left(x_{e}, g\right)}^{a \alpha}=\sum_{k=0 \quad{ }_{k}}^{w-x_{e}} P_{\left(x_{e}, g\right)}^{a a} \cdot F^{k}$ is the present value at age $x_{e}$ and for gender $g$ of 1 monetary unit of a lifetime pension payable in advance while the individual is healthy, indexed at rate $\alpha$ with a technical interest rate equal to $G$, and with $F^{k}=\left[\frac{1+\alpha}{1+G}\right]^{k}$.

${ }_{k} P_{\left(x_{e}, g\right)}^{a a}$ : Probability that a person (active) aged $x_{e}$ and of gender $g, k \in\left\{0,1, \cdots, w-\left(x_{e}\right)\right\}$ will reach age $x_{e}+k$ in the same state.

${ }^{\xi_{a j}} A_{\left(x_{e}, g\right)}^{a d_{j} \alpha}$ is the present actuarial value for an active person aged $x_{e}$ and of gender $g$ of the graded LTC annuity that supplements 1 monetary unit of the initial payment by percentage $\xi_{a j}$, where $j \in\{1,2, . . n\}$ and $0<\xi_{a 1}<\xi_{a 2}<\cdots<\xi_{a n}$.

$$
\xi_{a j} A_{\left(x_{e}, g\right)}^{a d_{j} \alpha}=\left(1+\xi_{a j}\right) \cdot\left[\begin{array}{c}
\sum_{k=1}^{w-x_{e}}\left({ }_{k-1} p_{\left(x_{e}, g\right)}^{a a} \cdot p_{\left(x_{e}+k-1, g\right)}^{a d_{j}}\right) \cdot F^{k} \cdot \ddot{a}_{\left(x_{e}+k, g\right)}^{d_{j} \alpha} \\
+ \\
\sum_{k=2}^{w-x_{e} j-1} \sum_{i=1}^{j-1}\left({ }_{k-1} p_{\left(x_{e}, g\right)}^{a d_{i}} \cdot p_{\left(x_{e}+k-1, g\right)}^{d_{i} d_{j}}\right) \cdot F^{k} \cdot \ddot{a}_{\left(x_{e}+k, g\right)}^{d_{j} \alpha}
\end{array}\right]
$$

$\ddot{a}_{\left(x_{e}+k, g\right)}^{d_{j} \alpha}$ : Present value at age $x_{e}+k$ for gender $g$ of 1 monetary unit of a lifetime pension payable in advance while the individual remains in any state of $j \in\{1,2, \ldots, n\}$ dependence.

$p_{\left(x_{e}+k-1, g\right)}^{a d_{j}}$ : Probability that a person (active) of gender $g$ aged $x_{e}+k-1$ will enter any state of dependence $d_{j}, j \in\{1,2, \ldots n\}$ this year.

${ }_{k-1} p_{\left(x_{e}, g\right)}^{a d_{j}}:$ Probability that a healthy person of gender $g$ aged $x_{e}$ will reach age $x_{e}+k-1$ in level $j \in\{1,2, \ldots, n\}$ of dependence.

$p_{\left(x_{e}+k-1, g\right)}^{d_{i} d_{j}}$ : Probability that an individual $(i \in\{1,2, \ldots n\}$-level dependent) of gender $g$ aged $x_{e}+k-1$ will reach age $x_{e}+k$ in a state of dependence $d_{j}, j \in\{1,2, \ldots n\}$.

The case for when the operating rule for indexing benefits in payment is $\alpha=G$ is interesting because the annuity factor can be expressed using the life expectancy of active persons disaggregated into healthy and unhealthy life years following the well-known Sullivan (1971) method:

$$
A F_{\left(x_{e}, g\right)}^{L C A(a, n)[\alpha=G]}
$$




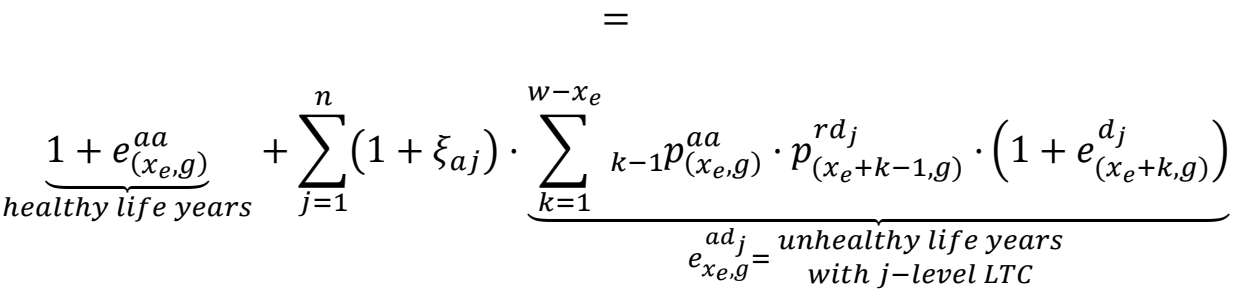

where,

$e_{\left(x_{e}, g\right)}^{a}=e_{\left(x_{e}, g\right)}^{a a}+\sum_{j=1}^{n} e_{\left(x_{e}, g\right)}^{a d_{j}}$ : Life expectancy (LE) for active persons aged $x_{e}$ of gender $g$. This can be broken down into the health statuses (active or dependent) they can expect to experience? It can be interpreted as the average time they will spend in the various (non-absorbing) states. It should be emphasized that this relationship is only true at the initial age.

$e_{x_{e}}^{a a}$ : Dependence-free life expectancy (DFLE) (or "healthy life years"). This indicates how many years of their total remaining life an active person aged $x_{e}$ can expect to live free of activity limitation. The difference between total LE and DFLE is the life expectancy with disability (LED).

$e_{\left(x_{e}, g\right)}^{a d_{j}}: j \in\{1,2, \ldots n\}$-level dependent life expectancy. This can be defined as the number of years an active person aged $x_{e}$ can expect to spend with $j \in\{1,2, \ldots n\}$-level activity limitation.

$e_{\left(x_{e}+k, g\right)}^{d_{j}}$ Life expectancy for a $j \in\{1,2, . . n\}$-level dependent person aged $x_{e}+k$, assuming that $e_{\left(x_{e}+k, g\right)}^{d_{n}}<e_{\left(x_{e}+k, g\right)}^{d_{n-1}}<\ldots \ldots<e_{\left(x_{e}+k, g\right)}^{d_{1}}<e_{\left(x_{e}+k, g\right)}^{a}$.

Finally, if the individual is in state $i$, i.e. their health state is not able, then the conversion rate can be expressed as:

$$
\begin{aligned}
& A F_{\left(x_{e}, g\right)}^{L C A\left(d_{i}, n\right)}=\overbrace{\sum_{k=0}{ }_{k} p_{\left(x_{e}, g\right)}^{d_{i} d_{i}}}^{\text {Continuously remains }} F^{k}+\overbrace{\sum_{k=1}^{W-x_{e}} \underbrace{\left(1-\xi_{i a}\right)}_{<1} \cdot{ }_{k} p_{\left(x_{e}, g\right)}^{d_{i} a} \cdot F^{k}}^{\text {Total recovery }} \\
& + \\
& \underbrace{\sum_{\text {( }}^{w-x_{e}} \sum_{j=1}^{i-1} \underbrace{\left(1-\xi_{i j}\right)}_{\text {Transitions to worse health states }} \cdot{ }_{k} p_{\left(x_{e}, g\right)}^{d_{i} d_{j}} \cdot F^{k}}_{\text {Transitions to better health states }}+\underbrace{\sum_{j-x_{e}} \sum_{j=i+1}^{n} \underbrace{\left(1+\xi_{i j}\right)}_{>1} \cdot{ }_{k} p_{\left(x_{e}, g\right)}^{d_{i} d_{j}} \cdot F^{k}}_{\sum_{k=1}}
\end{aligned}
$$

where,

${ }_{k} p \frac{d_{i} d_{i}}{\left(x_{e}, g\right)}$ : Probability that a person of level $d_{i}$ dependence of gender $g$ aged $x_{e}$ will reach age $x_{e}+k$ in the same state of dependence, or to put it another way, the probability that a person will remain continuously in the same state for $\mathrm{k}$ length of time. This is known as occupancy probability, state occupation probability or sojourn probability.

In fact this conversion factor corresponds to a more developed type of "impaired" or "enhanced" annuity ${ }^{10}$ in which changes of health states are explicitly modeled. If the demographic coherence of the data used is checked, and as long as the structure of uplifts for the

\footnotetext{
9 See Imai \& Soneji (2007) for details.

${ }^{10}$ These annuities work on the basis that, if the policyholder has a medical condition, they will have a shorter life expectancy than someone in a better state of health. In practice, the main conditions that qualify for an enhanced annuity are smoking, diabetes, high blood pressure, heart disease, cancer and kidney (renal) failure.
} 
LCA is well-designed, then:

$$
A F_{\left(x_{e}, g\right)}^{L C A(a, n)}>A F_{\left(x_{e}, g\right)}^{L C A\left(d_{1}, n\right)}>\cdots>A F_{\left(x_{e}, g\right)}^{L C A\left(d_{n}, n\right)}
$$

The authors are aware that if gender, age and initial health state do not account for all key differences in mortality ${ }^{11}$ (and morbidity), then those socio-economic groups with shorter life expectancy cross-subsidize groups that systematically live longer ${ }^{12}$.

Once the actuarial factors have been given, it is straightforward to compute the embedded redistribution when using gender-neutral factors to determine the initial payment of LCAs:

$$
R_{\left(x_{e}, g\right)}=\frac{A F_{\left(x_{e}, g\right)}^{L C A(a, n)}}{A F_{\left(x_{e}, u\right)}^{L C A(a, n)}}-1 \text {, with } g \in\{m, f\}
$$

This indicates the increase or reduction in the annuitant's annual benefits due to the application of community rating instead risk rating, or in other words, it shows how ex-ante systematic differences in mortality and morbidity affect the expected lifetime value of the LCA ${ }^{13}$.

This indicator is actually very close to the so-called "money's worth" measure that has been widely used to assess whether annuities are fairly valued. This measure (Warshawsky, 1988; Cannon \& Tonks, 2016) compares the expected present value of the annuity payments with the price paid for the annuity and is calculated using the term structure of interest rates at the date of calculation and future life expectancy. Under a PAYG pension system (Clingman et al., 2014), the money's worth ratio is the ratio of the present value of expected benefits to the present value of expected payroll taxes (contributions) for an individual or a cohort of workers.

Under the assumption that the value of the gender-actuarial factor is the price paid for the LCA and equivalent to the accumulated capital from contributions made by the contributor valued at the age of becoming a beneficiary, then the gender money's worth can be expressed as:

$$
M W_{\left(x_{e}, g\right)}=1+R_{\left(x_{e}, g\right)}=\frac{A F_{\left(x_{e}, g\right)}^{L C A(a, n)}}{A F_{\left(x_{e}, u\right)}^{L C A(a, n)}}=\frac{\text { Present value of expected benefits }}{\text { Accumulated capital from contributions }}
$$

A value greater than 1 for this ratio indicates that, on a present value basis, the benefits from a gender perspective exceed the theoretical cost of purchasing the LCA. It is obvious that under gender-specific pricing the gender money's worth would be exactly equal to 1, given that it does not take into account the existence of administrative and regulatory costs or the normal profits taken by the annuity provider (i.e. the State in a PAYG system).

Finally, it might also be very informative to break down the gender redistribution by health states:

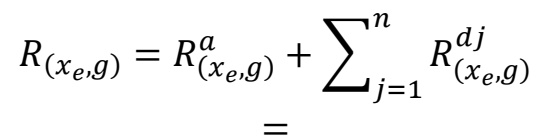

\footnotetext{
11 On this subject, interested readers can consult the papers by Brown \& McDaid (2002), Villegas \& Haberman (2014) and Ayuso et al. (2016), for example.

12 As noted earlier, this lies outside the scope of this paper.

${ }^{13}$ A different issue is ex-post redistribution. An LCA creates a redistribution ex-post as some individuals die early and/or spend less time than initially expected in bad health, transferring their resources to those who die later and/or spend more time than initially expected in states of dependence.
} 


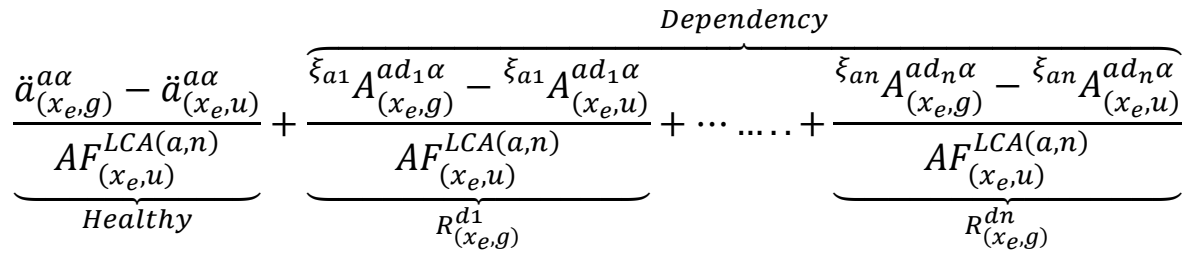

\section{Numerical illustration based on data from Australia and the US}

Because there is accurate biometric gender information published for two developed countries (Australia and the US) that is suitable for use in the model developed above, this section shows the impact that the use of unisex rates might have on redistribution between genders in a theoretical PAYG system covering retirement and LTC benefits.

The exercise should be viewed simply as an illustration because the structure of the uplifts and decreases and the rate used for discounting pension wealth are fairly arbitrary and the proposed scheme is not yet in operation in any country. An additional objective of this section is to convey an idea of how variable the results can be depending on the annuitant's initial health status.

The section is divided into two parts:

(a) Scenario 1 comprises a numerical example performed using data from Hariyanto et al. (2014a, 2014b) for Australia. Given that their papers do not provide all the probabilities by age that we need to perform our numerical example, a cubic smoothing spline ${ }^{14}$ using $\mathrm{R}$ software has been fitted to the data in order to obtain them.

(b) Scenario 2 contains a numerical example developed using data obtained from Robinson's (1996) care transition model (CTM) for the US. This model has been widely used by many researchers ${ }^{15}$ and in the US insurance industry, particularly in LTC insurance, to develop premiums and reserves and do other essential computations, although the data upon which it is based are now over 30 years old.

There are four assumptions common to both parts. First, retirement eligibility is set for ages ranging from 61 to 70 . In most developed countries at least $95 \%$ of contributors retire within this range of ages ${ }^{16}$. In Australia the minimum age for receipt of superannuation benefits is 60 for people born after June 30 1964, whereas the Age Pension is payable from age 65 for both men and women. The pension age will increase by six months every two years from 2017 until it reaches 67 by 2023. In the US the current full retirement age for Social Security purposes is 66 . For those born after 1954, the retirement age will gradually increase (by two months per birth year) until it reaches 67 for those born in 1960 or later. However, 62 is the age when the contributor is first eligible to receive Social Security retirement benefits ${ }^{17}$.

Second, in principle the annuitant is healthy (able) when they become a beneficiary at any age within the range of retirement ages. Third, the financial factor used to discount pension wealth is $\left(F^{k}=\left[\frac{1}{1.02}\right]^{k}\right)$, which also means that the initial benefit remains constant over time in real terms (pensions in payment are indexed to prices).

\footnotetext{
${ }^{14}$ https://stat.ethz.ch/R-manual/R-devel/library/stats/html/smooth.spline.html

${ }^{15}$ Robinson's paper has been cited in over 68 academic works, most of them published in prestigious journals:

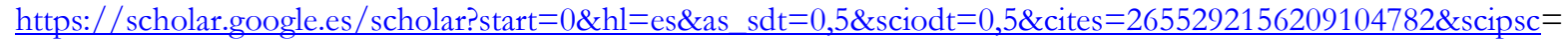

${ }^{16}$ In Sweden, for example (TSPS, 2016), 95.8\% of the 1944 birth cohort retired between ages 61 and 70, while in the case of Spain in 2016, $98.59 \%$ of new retirement pensioners were in this range of ages. Details for Spain can be found at:

http://www.segsocial.es/Internet 1/Estadistica/Est/Pensiones y pensionistas/Altas y Bajas de Pensiones Cont ributivas/AIniBdef2k11/index.htm

${ }^{17}$ Full details for both countries can be found in OECD (2015).
} 
And fourth, in order to compute the gender-neutral actuarial factor, we follow the current practice in insurance companies (Chen \& Vigna, 2017), which seems to be to calculate a unisex tariff obtained by mixing the life tables, in our case mortality and morbidity tables, for the two sexes (see Appendix 1). However, contrary to the usual practice in insurance, we have not introduced a correction giving more weight to the table for the high-risk gender (females).

Finally, since the annuity rate (also) depends on the indexation policy, we also analyze the impact on cross-subsidization for when the operating rule for indexing benefits in payment is $\alpha=G=$ 0.02 .

\section{1) Scenario 1 based on biometric assumptions for Australia.}

The data used to perform this numerical example were obtained from the papers by Hariyanto et al. (2014a, 2014b). Their model provides five health statuses as shown in Figure 1: one healthy and four dependent (with core activity limitation in their terminology). In state $a$ the individual is able or healthy with no activity limitation. Four levels of core activity limitation are determined on the basis of whether a person needs help with, has difficulty with or uses aids or equipment for any of the core activities (communication, mobility and self-care). In state $d_{1}$ the individual has mild limitations. In state $d_{2}$ they have moderate limitations insofar as they need no help but have difficulty with a core activity task. In state $d_{3}$ they have severe limitations. In state $d_{4}$ the individual has profound limitations, meaning they are unable to do, or always need help with, a core activity task. And finally in state $e$ the individual is dead.

It is also assumed that people in any state of core activity limitation can only improve by one category over a one-year interval, if and only if they survive the year and do not deteriorate to a more severe state of dependence.

Figure 1: The model using data from Hariyanto et al. (2014a, 2014b)

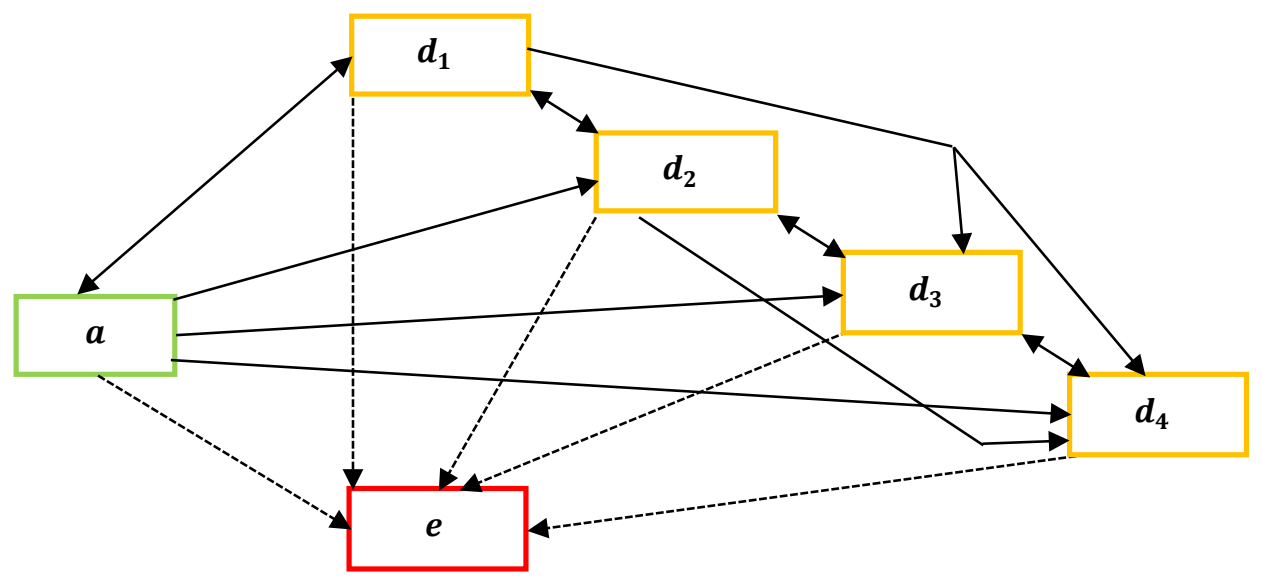

Source: Own

In line with the predefined dependence states, Table 1 shows the uplifts and decreases $\left(\xi_{i j}\right)$ to be applied depending on the transitions between the various states taken into account in the numerical example. We use the same values as in Pla-Porcel et al. (2016b).

The diagonal of the matrix (shaded cells) embedded in Table 1 shows a zero value because it denotes where the individual's health status remains unchanged. The cells with the abbreviation n.a. indicate where this transition is it not possible.

In principle, given the initial assumption made about the retired person's health status (able), only the first row (shaded) is used for computing the actuarial factor. A different row would need to be used if the assumption about the health of the pensioner were to change, as we will see later. 
To give an example, when an active person becomes dependent at level $3\left(a, d_{3}\right)$, the amount of the annuity doubles, given that $\xi_{a 3}=1$. However, the amount of benefit is reduced by $25 \%$ when a level 3 dependent makes a transition to level $2\left(d_{3}, d_{2}\right)$.

\begin{tabular}{|c|c|c|c|c|c|}
\hline \multicolumn{6}{|c|}{$\begin{array}{l}\text { Table 1: The uplifts and decreases }\left(\xi_{i j}\right) \text { to be applied depending } \\
\text { on the transitions between the various states. }\end{array}$} \\
\hline \multirow{2}{*}{ Starting status, $i$} & \multicolumn{5}{|c|}{ Ending status, $j$} \\
\hline & $a$ & $d_{1}$ & $d_{2}$ & $d_{3}$ & $d_{4}$ \\
\hline$a$ & 0.00 & 0.25 & 0.50 & 1.00 & 1.50 \\
\hline$d_{1}$ & -0.20 & 0.00 & 0.20 & 0.60 & 1.00 \\
\hline$d_{2}$ & n.a. & -0.17 & 0.00 & 0.33 & 0.67 \\
\hline$d_{3}$ & n.a. & n.a. & -0.25 & 0.00 & 0.25 \\
\hline$d_{4}$ & n.a. & n.a. & n.a. & -0.20 & 0.00 \\
\hline
\end{tabular}

Figure 2 shows life expectancy and expected time in dependence for both genders, labeled $\mathrm{F}$ and M. The results clearly show differences in mortality by gender and health state and contain no surprises.
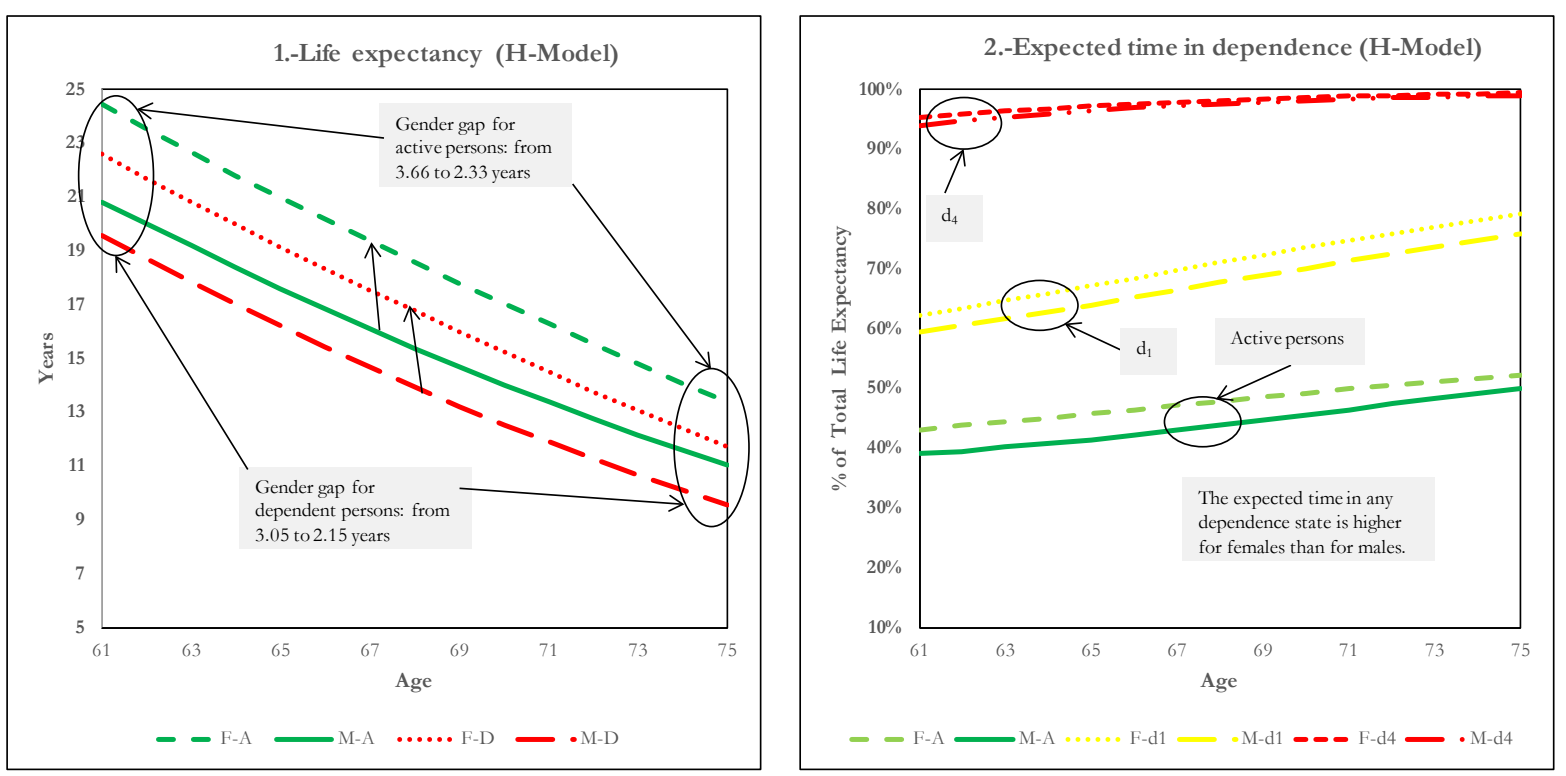

Figure 2: Life expectancy and expected time in dependence ( $\mathrm{H}$ model)

Graph 1 in Figure 2 shows life expectancy for active (F-A and M-A) and dependent (F-D and MD) persons by gender. For the range of ages represented, the gender gap in life expectancy fluctuates from 3.66 to 2.33 years for the healthy group whereas, for the dependent persons, females outlive males by between 3.05 and 2.15 years. ${ }^{18}$ Generally speaking, the gender gap tends to decrease in absolute value as the individuals get older.

Graph 2 in Figure 2 represents the expected time spent in a situation of dependence for active persons and for two specific levels of dependence $\left(d_{1}\right.$ and $\left.d_{4}\right)$ as a percentage of total life expectancy. For the whole range of ages, the expected time spent in any dependence state is higher for females than for males, and this is true irrespective of the initial health state. This pattern is indicative of the so-called "male-female health-survival paradox" (Luy \& Minagawa, 2014), a phenomenon observed in developed countries in which women experience greater longevity but higher rates of disability and poor health than men. A large number of studies have

\footnotetext{
${ }^{18}$ Similar differences were reported by Nusselder et al. (2010) for EU-15 populations.
} 
examined this paradox, but relatively little is known about the mechanisms underlying it, and obviously this goes far beyond the scope of this paper.

Detailed information about life expectancy in years at ages 61 and 70 and the percentage of total life expectancy likely to be spent in each of the states can be found in Appendix 2 (Tables A2-1 and A2-2 for females and Tables A2-3 and A2-4 for males). The diagonal of the matrices embedded in these tables shows life expectancy in years and the percentage of life expectancy likely to be spent in the same health status. The expected number of years allocated to the possible range of health states depends on the starting status by age.

From a demographic standpoint, the data obtained from Hariyanto et al. (2014a, 2014b) are coherent because life expectancy decreases when an individual's disability state worsens. A recent study performed using Japanese data (Tanaka, 2016) shows the same pattern.

As expected, with these biometric assumptions the use of gender-neutral annuities implies redistribution from males to females, as can be seen in Graph 1 in Figure 3 for the case where the annuitant's initial heath state is able when they become a beneficiary (see Tables A3-1 and A3-2 in Appendix 3). More specifically, this graph shows ex-ante redistribution in two cases: 1.-the annuity includes LTC coverage (LCA annuity), labeled as F-R+LTC and M-R+LTC for females and males respectively, and 2.-the annuity pays the same benefit irrespective of the health state of the individual, labeled as F-R and M-R.
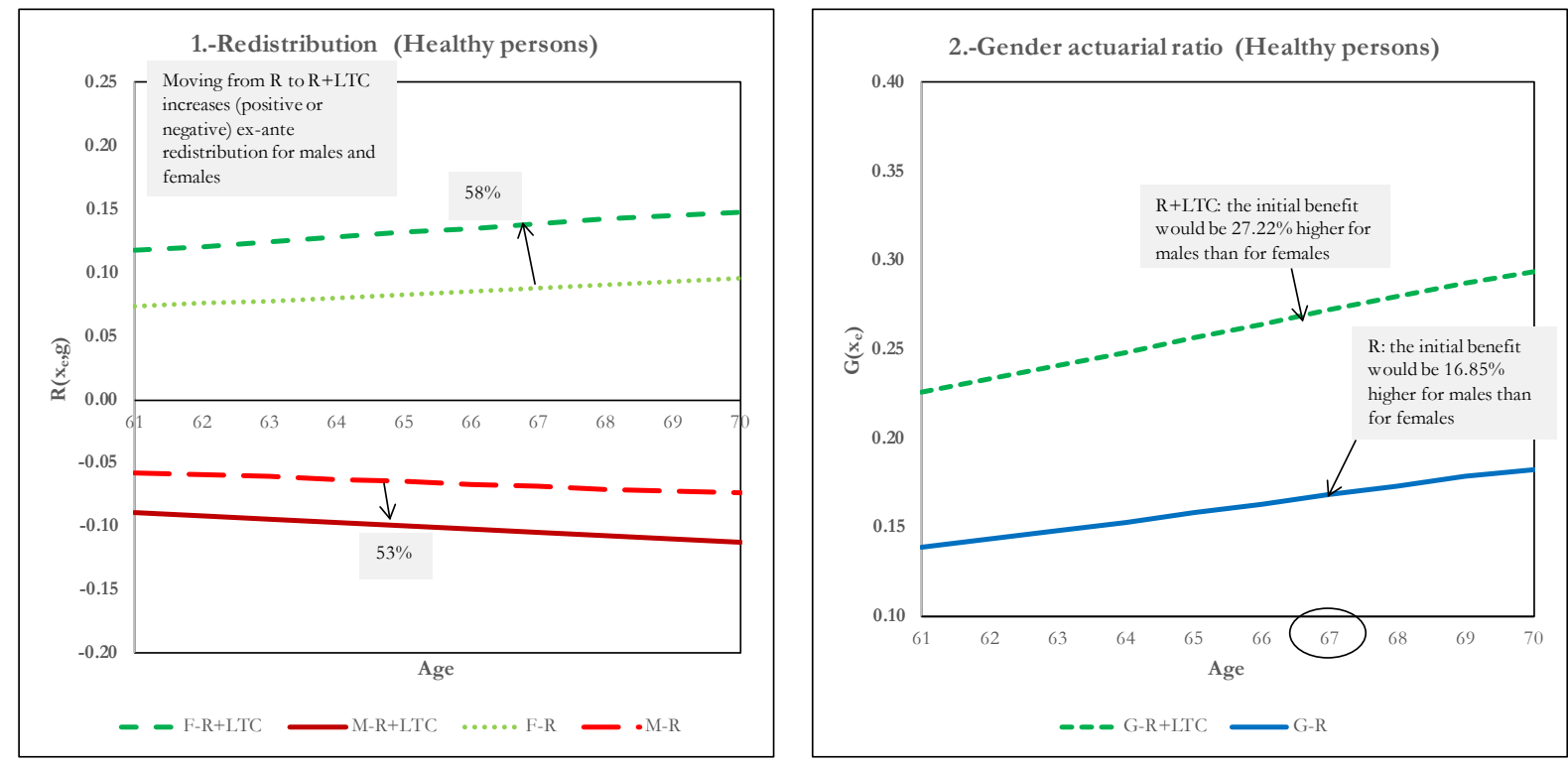

Figure 3: Ex-ante redistribution and gender actuarial ratio for healthy persons (H model)

On average for females (F-R +LTC), the use of a gender-neutral actuarial factor to compute the initial benefit increases the initial payment by $13.32 \%$ in the combined scheme. The effect on males (M-R+LTC) is a reduction of $10.08 \%$ of the initial payment if the benefit had been computed using gender-specific rates.

At the ordinary age of eligibility for retirement benefits in most OECD countries, i.e. age 67, in the combined system and using community rating it could be said that the gender money's worth for females would be 1.1387, i.e. on a present value basis, benefits would exceed the theoretical cost of acquiring an LCA by $13.87 \%$. For males this indicator would be 0.8951 , meaning the annuitant would get only 0.8951 monetary units for each unit contributed.

It can be seen that the effect of converting retirement benefit into an LCA with graded benefits on the basis of ex-ante redistribution is quite important (i.e. moving from F-R to F-R+LTC for 
females and from M-R to M-R+LTC for males). On average, cross-subsidization increases at a rate of around $53 \%$ and $58 \%$ for males and females respectively.

Graph 2 in Figure 3 shows the so-called "gender actuarial ratio", $G_{\left(x_{e}\right)}=\frac{A F_{\left(x_{e}, f\right)}^{L C A(a, n)}}{A F_{\left(x_{e}, m\right)}^{L C A(a, n)}}-1$, which computes the relative difference in the initial benefit between males and females if it were possible to use gender risk rating for pricing the system's initial benefit (see Table A3-3 in Appendix 3). As the value of $G_{\left(x_{e}\right)}$ increases when moving from a system with retirement $(\mathrm{G}-\mathrm{R})$ to a system with retirement plus LTC coverage (G-R+LTC), the ex-ante redistribution also increases.

For an annuitant aged 67 , in the combined system the initial benefit would be $27.22 \%$ higher for males than for females if it were allowed to use gender-distinct rates for computing the system's initial benefit, whereas in the case of an old-age scheme it would be "only" $16.85 \%$ higher.
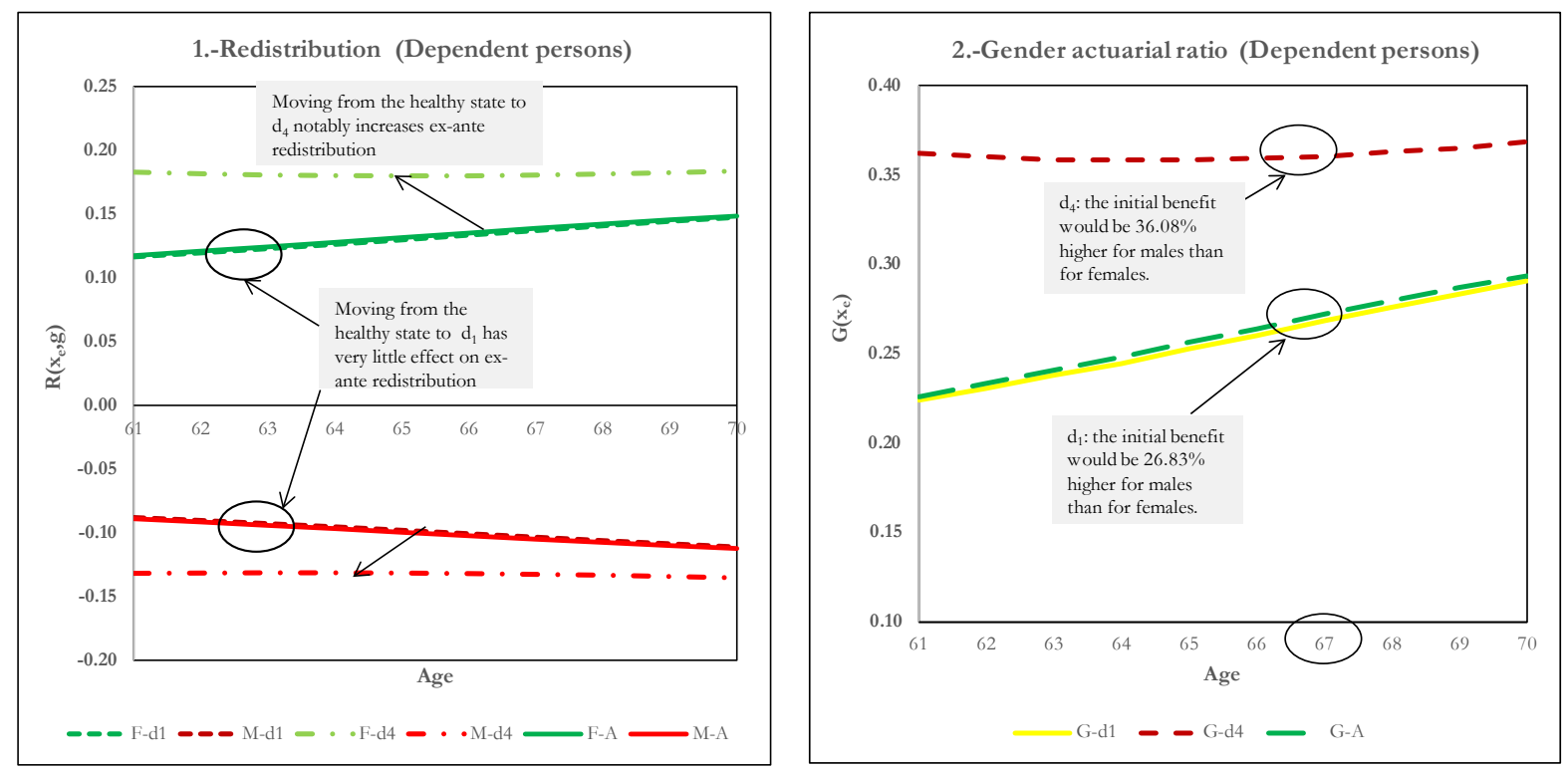

Figure 4: Ex-ante redistribution and gender actuarial ratio for dependent persons ( $\mathrm{H}$ model).

So what might happen if the annuitant's initial heath state is not able when they become entitled to receive benefits? Figure 4 helps us to answer this question. It shows the ex-ante redistribution and gender actuarial ratio for two types of dependent person, those in the least $\left(d_{1}\right)$ and the most $\left(d_{4}\right)$ severe states of dependence, and compares them with the values for active persons (see Table A3-1 in Appendix 3).

Graph 1 in Figure 4 shows that the effect on gender ex-ante redistribution is (very) significant when the annuitant's initial heath state is the most severe $\left(d_{4}\right)$. The situation for the least severe $\left(d_{1}\right)$ is less relevant, and in fact the redistribution by age is lower than for active persons (males and females). Graph 2 in Figure 4 sheds light what can be seen in Graph 1 (see Table A3-3 in Appendix 3). Moving from an able state (G-A) to a state in which the individual has mild limitations $\left(G-d_{1}\right)$ hardly affects the gender actuarial ratio, whereas the reverse is true when moving to the most severe state $\left(\mathrm{G}-\mathrm{d}_{4}\right)$. Under the assumption that the individual is awarded benefit at age 67 in the most severe state of dependence (like with "impaired" or "enhanced" annuities) and using gender specific conversion factors, the initial benefit would be $36.08 \%$ higher for males than for females, while if the initial state were the least severe degree of dependence, the initial benefit would be $26.83 \%$ higher. 
These results are endorsed by the biometric assumptions used. As can be seen in Appendix 2, (Tables A2-1 and A2-2 for females and Tables A2-3 and A2-4 for males), state $d_{4}$ involves noticeable differences in mortality and morbidity in comparison to the other states.

To be more specific, if the male's initial heath state were the most severe $\left(d_{4}\right)$ and gender-specific rates could not be used to calculate the system's initial benefit, on average there would be a reduction of around $13.24 \%$ on the initial award. In the case of women, the benefit would increase by $18.12 \%$.

In short, it would be no exaggeration to say that the initial health of the individual has an important effect on ex-ante redistribution, and very much depends on the data and the structure of the predefined uplifts.

As mentioned earlier, another important issue is the indexation policy used. Does this have a significant effect on ex-ante redistribution? The answer can be found in Figure 5, which shows a comparison of results for when the operating rule for indexing benefits in payment is $\alpha=G=$ 0.02 and the initial indexation rule means that the initial benefit remains constant over time in real terms (pensions in payment are indexed to prices). The detailed results can be found in Tables A3-4, A3-5 and A3-6 in Appendix 3.
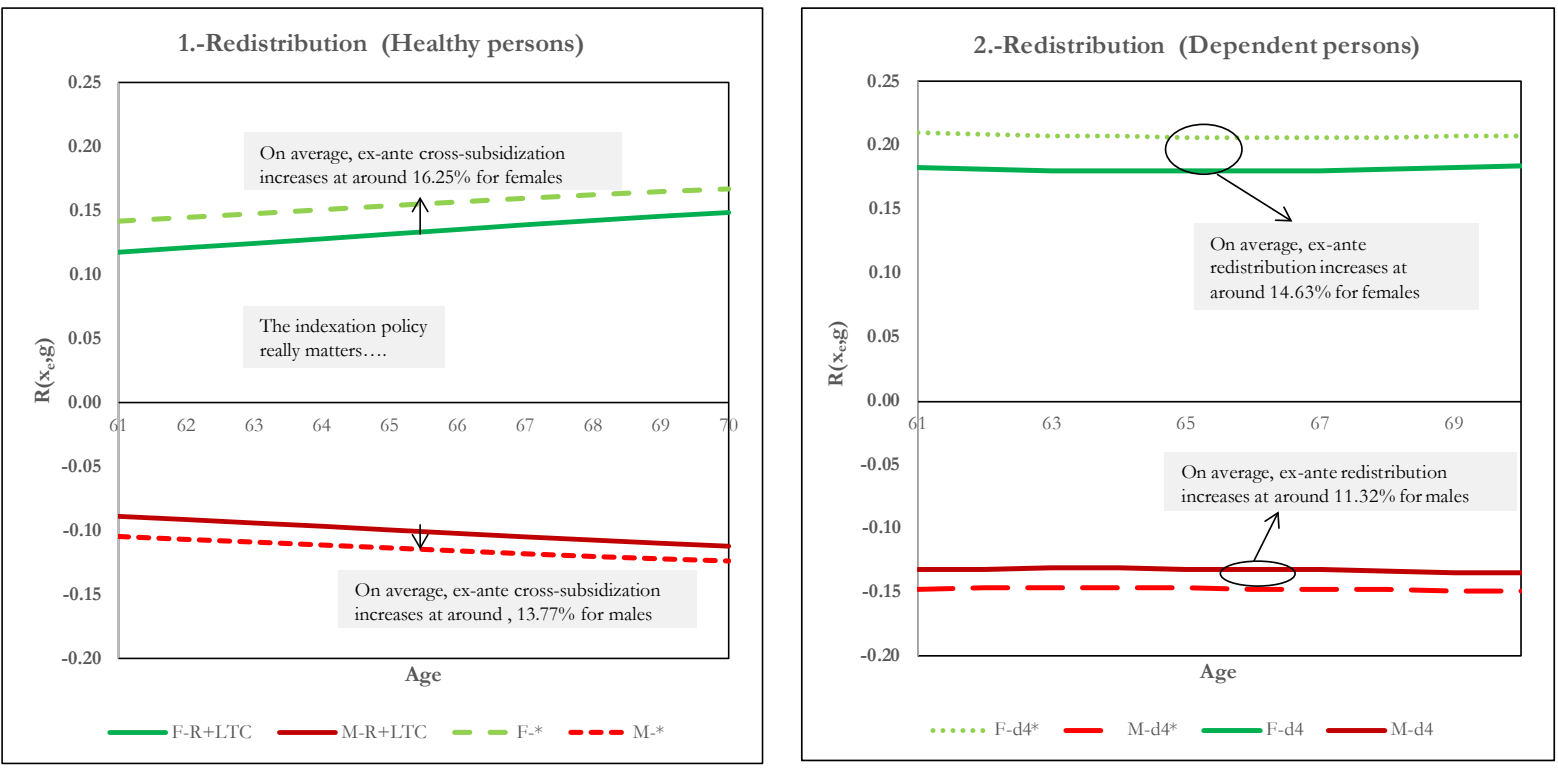

Figure 5: Ex-ante redistribution and indexation policy ( $\mathrm{H}$ model).

The indexation policy really matters because the growth of benefits in real terms increases redistribution, given that it benefits females as they have a higher probability of reaching older ages with a worse disability status than males. When the indexation policy is changed and the person's initial health status is able, ex-ante cross-subsidization increases by an average of around $13.77 \%$ and $16.25 \%$ for males and females respectively. For the case in which the individual's initial health status is the most severe state of dependence, the increase in redistribution is not as high as before but can still be considered very important: $11.32 \%$ for men and $14.63 \%$ for women.

To end this section it is worth exploring the gender redistribution by health states and age (formula 8). Table A3-7 in Appendix 3 provides the figures for this. On average for females, 83\% of the ex-ante redistribution is caused by the most severe disability health states. A very similar figure $(81 \%)$ is calculated for males. For a given set of biometric data, the weight in the redistribution is greatly influenced by the design of the uplift structure. Table A3-8 in Appendix 3 shows the results for when being in a state of dependence does not increase payments. In this 
case, for females an average of $65 \%$ of ex-ante redistribution is caused by disability health statuses, whereas for males the percentage is only $62 \%$. In short, given a set of mortality and morbidity assumptions, the higher the increases associated with the disability states, the higher the cross-subsidization produced by these states.

\section{b) Scenario 2 based on biometric assumptions for the US.}

The data used to perform the second numerical example were obtained from Robinson's (1996) care transition model (CTM). The "life transitions" demonstration implemented by Chandler (2007) using Mathematica software provided the basic data for computing transition rates between the seven states into which the data divided health (Figure 6). Robinson's CTM provides seven health states that differ according to three variables: (a) the number of IADLs impaired, (b) the number of ADLs impaired, and (c) whether there is "cognitive impairment".

Figure 6: The model using data from Robinson (1996)

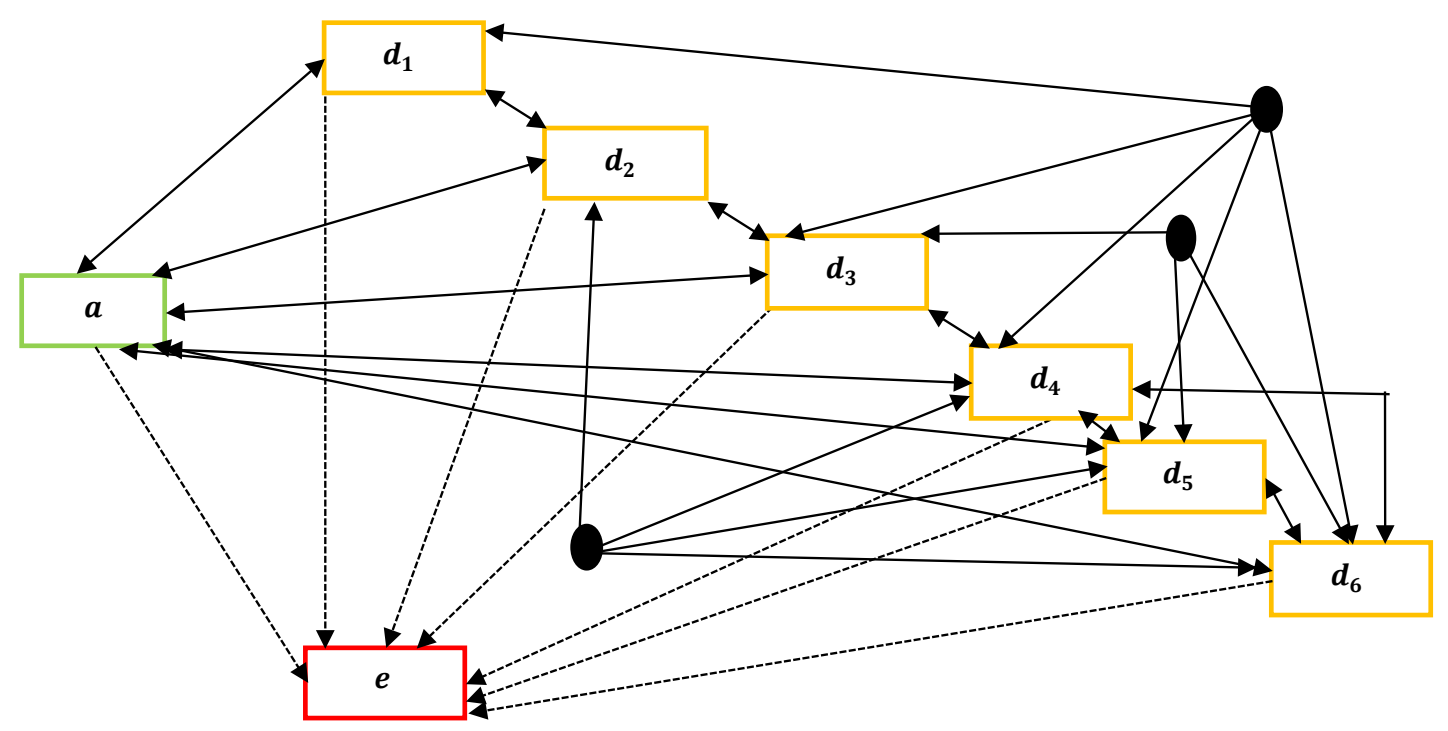

Source: Own

In state $a$ the individual has no impaired IADLs, no impaired ADLs and no cognitive impairment. In state $d_{1}$ the individual has one impaired IADL, no impaired ADLs and no cognitive impairment. In state $d_{2}$ the individual has one impaired ADL and no cognitive impairment. In state $d_{3}$ the individual has two impaired ADLs and no cognitive impairment. In state $d_{4}$ the individual has three or more impaired ADLs and no cognitive impairment. In state $d_{5}$ the individual has fewer than two impaired ADLs but has cognitive impairment. In state $d_{6}$ the individual has more than one impaired ADL and cognitive impairment. In state $e$ the individual is dead.

\begin{tabular}{|c|c|c|c|c|c|c|c|}
\hline \multirow{3}{*}{ Starting status, $i$} & \multirow{2}{*}{\multicolumn{7}{|c|}{ Ending status, $j$}} \\
\hline & & & & & & & \\
\hline & $a$ & $d_{1}$ & $d_{2}$ & $d_{3}$ & $d_{4}$ & $d_{5}$ & $d_{6}$ \\
\hline$a$ & 0.00 & 0.25 & 0.50 & 0.75 & 1.00 & 1.25 & 1.50 \\
\hline$d_{1}$ & -0.20 & 0.00 & 0.20 & 0.40 & 0.60 & 0.80 & 1.00 \\
\hline$d_{2}$ & -0.33 & -0.17 & 0.00 & 0.17 & 0.33 & 0.50 & 0.67 \\
\hline$d_{3}$ & -0.43 & -0.29 & -0.14 & 0.00 & 0.14 & 0.29 & 0.43 \\
\hline$d_{4}$ & -0.50 & -0.38 & -0.25 & -0.13 & 0.00 & 0.13 & 0.25 \\
\hline$d_{5}$ & -0.56 & -0.44 & -0.33 & -0.22 & -0.11 & 0.00 & 0.11 \\
\hline
\end{tabular}




\begin{tabular}{l|l|l|l|l|l|l|l|}
$\boldsymbol{d}_{\mathbf{6}}$ & -0.60 & -0.50 & -0.40 & -0.30 & -0.20 & -0.10 & 0.00 \\
\hline
\end{tabular}

In line with the predefined dependence states, Table 2 shows the (arbitrary) uplifts and decreases $\left(\xi_{i j}\right)$ to be applied depending on the transitions between the various states that are taken into account in the numerical example. As in the previous subsection, the diagonal of the matrix (shaded cells) embedded in Table 2 shows a zero value because it denotes where the individual's health status remains unchanged. Unlike what was shown in the previous subsection, Table 2 has numerical values in all its cells because all transitions are possible and have a positive probability value according to Robinson's (1996) CTM.

For the sake of brevity, we omit the figures given in the previous subsection, but, in Appendix 2, Tables A2-5 to A2-8 replicate the same mortality and morbidity information presented for the previous numerical illustration, and Tables A3-9 to A3-16 in Appendix 3 show detailed information on the redistribution and gender actuarial factors.

With this set of biometric data, the most relevant results are the following:

1.-For females the use of a gender-neutral actuarial factor to compute the initial benefit increases the initial payment by an average of $12.94 \%$ in the combined scheme $(13.32 \%$ for the Australian case). The effect on males is a reduction of $9.48 \%$ on the initial payment if the benefit had been computed using gender-specific rates $(10.08 \%$ for the first numerical example). It could be said that, in spite of the very different biometric data, the results are surprisingly similar for both males and females in both countries.

Under the assumption that the individual reaches retirement at age 67 in an able status and that it is possible to use gender-distinct rates for computing the system's initial benefit, in the combined system the initial benefit would be $25.56 \%$ higher for males than for females. A very similar figure was reported in the previous subsection $(27.22 \%)$ for the scheme covering LTC. In the case of an old-age scheme the initial benefit would be $20.15 \%$ higher for men than for women. These results are in line with the differences in morbidity observed in both sets of biometric data.

2.-The effect of converting retirement benefit into an LCA with graded benefits on ex-ante redistribution is not as great as in the Australian case, where cross-subsidization increases on average by around $20 \%$ and $27 \%$ for males and females respectively. This is a foreseeable result given that the data from Australia show that active persons have a higher life expectancy than in the case of the USA, where a lower percentage of life expectancy is likely to be spent in the same health status, i.e. the expected time spent in any dependence state is far higher for the Hariyanto et al. (2014a, 2014b) assumptions than for Robinson's (1996).

3.-If the male's initial heath state were the most severe $\left(d_{6}\right)$ and it were impossible to use genderspecific actuarial factors to calculate the system's initial benefit, on average there would be a reduction of around $16.08 \%$ on the initial payment. For females there would be an increase in benefit of $23.69 \%$. Gender redistribution in this case is higher than in the previous section (13.24\% and $18.12 \%$ for males and females), but a direct comparison of results for both sets of biometric data is not totally proper because no appropriate equivalence can be established between the categorized groups of disabled in both sets of assumptions and there are differences in the structure of the uplifts in both cases.

4.-On average, ex-ante cross-subsidization increases by around $16.79 \%$ and $12.05 \%$ for males and females respectively when the indexation policy is changed and the person's initial health status is able. By contrast, the previous section reported a higher increase in redistribution for females $(16.25 \%)$ than for males $(13.77 \%)$, but again the figures do not diverge very much. For the case in which the individual's initial health status is the most severe state of dependence, the increase in redistribution for males is not as high as before $(9.31 \%)$, but the reverse is true for females $(13.32 \%)$. 
5.- Finally, as far as gender redistribution by health states and age is concerned, for females an average of $68 \%$ of the ex-ante redistribution is caused by disability health states, with the more severe states of dependence being by far the most important. A very similar figure $(62 \%)$ is calculated for males. These results are different from those calculated for the case of Australia, in which the redistribution allocated to non-healthy states was higher. As mentioned earlier, for a given set of biometric data the weight in the redistribution is greatly influenced by the design of the uplift structure. Table A3-16 in Appendix 3 shows the results for a case in which being in a state of dependence does not increase payments, where on average only $50 \%$ of the ex-ante redistribution for females and $49 \%$ for males is caused by disability health statuses. These results are slightly lower than in the Australian case.

\section{4.-Concluding comments and future research.}

Most people in developed countries are in favor of having a gender-equal pension system that would recognize the unequal burden borne by women in labor markets and families, and which would pool and share the welfare risks that that inequality entails. Even in the field of private insurance (Schmeiser et al., 2014), gender and age are the risk classification factors least accepted by customers. But the other side of the coin is that legal restrictions may lead to a situation whereby lower-risk contributors pay higher social contributions than those corresponding to their true (mortality and morbidity) risk and cross-subsidize high-risk affiliates, who would pay lower premiums than those justified by the actuarial equivalence principle.

In line with Schokkaert and Van Parijs (2003), the answers to our basic pension policy questions should not be dictated by public opinion, dominant ideology or consumer preferences. Our response regarding the use of gender-risk factors must be based on an objective analysis of the current available data and a coherent conception of justice from an actuarial point of view.

Bearing all this in mind, we have assessed gender redistribution resulting from the use of unisex conversion factors to compute the initial benefit of LCAs embedded in a PAYG pension system. This idea, which nowadays could be considered politically incorrect, comes naturally to actuarial thinking given that there are well-documented gender differences in mortality and morbidity, and consequently the cost of providing LCAs varies greatly between men and women. Additionally, under the irrevocable principle of transparency, modern societies demand access to information on this subject.

We use a method based on actuarial factors to disentangle the hidden redistribution of a notional LCA with graded benefits. Generally speaking, converting retirement benefit into an LCA with graded benefits within a pre-existing public PAYG pension scheme using gender-neutral annuity factors involves a large increase in ex-ante gender redistribution in comparison to a system without LTC coverage.

According to our calculations based on relevant statistical data for two developed countries, the level of gender redistribution is by no means irrelevant. In spite of the very different biometric data, the results are surprisingly similar for both countries. For a given structure of uplifts, the use of a gender-neutral actuarial factor to compute the initial benefit for females increases the initial payment by an average of $12.94 \%$ (US) and $13.32 \%$ (Australia) in the combined scheme. Meanwhile males could see a reduction in pension income from LCAs of between $9.48 \%$ (US) and $10.08 \%$ (Australia) of the initial payment compared to what they would have received using gender-specific rates.

Under the assumption that the individual reaches retirement at age 67 in an able state, the use of community rating means that women, on a present value basis, would receive 1.135 monetary units for each unity contributed, whereas males would receive only 0.90 . It may be that these figures show that using community rating would involve too much gender redistribution, at least 
from an actuarial point of view. Nevertheless, this would be a temporary (long lasting?) situation, given that gender differences in mortality (and morbidity?) are expected to narrow in coming decades according to some of the papers quoted earlier. This, however, remains to be seen.

So what are these figures telling us? Under the above assumption for the individual, if it were possible to use gender-distinct rates for computing the system's initial benefit, this would be $25.56 \%$ (USA) and $27.22 \%$ (Australia) higher for males than for females. This fact should not be hidden from annuitants on the basis of gender equality. It is not a good idea to compensate for the problems borne by females in the accumulation phase - mainly due to their lesser presence on the labor market, the frequency of part-time working, and wage differences - with actuarial discrimination against males in the pay-out phase in the shape of unfair actuarial rates.

As we have shown, it is not only age and gender that are important when computing the initial benefit; the initial health state when the individual becomes a beneficiary also matters. By and large, if the individual's initial heath status were the one of most severe states, and if it were not possible to use gender-specific actuarial factors when awarding the system's initial benefit, then gender redistribution on average would be (much) higher than in the case of an individual in a healthy state.

In short, risk equalization based on the "equal treatment" of men and women may not be fair, given that age, gender and health states are very significant risk factors when computing the initial benefit in a system covering retirement and LTC.

Finally, based on this paper, at least two directions for future research can be identified. First, to explore how ex-ante redistribution would be affected if the rule to compute the gender-neutral actuarial factor obtained by mixing the mortality and morbidity tables of both genders were changed to include the use of a unisex fairness principle, which would imply the use of a corresponding unisex fair actuarial factor. The second direction would be to explore the idea of taking the beneficiary's health status into account when calculating the initial benefit within a PAYG retirement system and the consequences this would have for the whole cohort of pensioners (able and dependent persons).

\section{5.-References}

Aseervatham, V., Lex, C. \& Spindler, M. (2016), How Do Unisex Rating Regulations Affect Gender Differences in Insurance Premiums? The Geneva Papers on Risk and Insurance, 41(1), 128160.

Aubert, P., Duc, C. \& Ducoudré, B. (2013), French Retirement Reforms and Intragenerational Equity in Retirement Duration, De Economist 161(3), 277-305.

Ayuso, M., Bravo, J. M \& Holzmann, R. (2016), Addressing Longevity Heterogeneity in Pension Scheme Design and Reform, IZA DP No. 10378

Barnay, T. (2007), Redistributive Impact of Differential Mortality in the French Pay-As-You-Go System, The Geneva Papers on Risk and Insurance, 32(4), 570-582.

Bonnet, C. \& Hourriez, J.-M. (2012), Gender equality in pensions: what role for rights accrued as a spouse or a parent? Population-E, 67, 123-146.

Brown, R.L. \& McDaid, J. (2002), Factors Affecting Retirement Mortality, North American Actuarial Journal, 7(2), 24-43.

Cannon, E. \& Tonks, I. (2016), Cohort mortality risk or adverse selection in annuity markets? Journal of Public Economics, 141, 68-81.

Case, A. \& Paxson, C. (2005), Sex differences in morbidity and mortality. Demography 42(2), 189214. 
Caselli, G., Peracchi, F., Barbi, E. \& Lipsi, R. M. (2003), Differential Mortality and the Design of the Italian System of Public Pensions. Labour, 17: 45-78.

Chandler, S. J. (2007), "Life Transitions" from the Wolfram demonstrations project. http://demonstrations.wolfram.com/LifeTransitions

Chen, Y.-P. (1994), Financing Long-Term Care: An Intragenerational Social Insurance Model. The Geneva Papers on Risk and Insurance, 19(73), 490-495.

Chen, Y.-P. (2001), Funding Long-term Care in the United States: The Role of Private Insurance, The Geneva Papers on Risk and Insurance, 26(4), 656-666.

Chen, Y.-P. (2003), Applications of the Trade-Off Principle in Both Public and Private Sectors, Journal of Aging and Health, 15(1), 15-44.

Chen, A. \& Vigna, E. (2017), A unisex stochastic mortality model to comply with EU Gender Directive, Insurance: Mathematics and Economics, http://dx.doi.org/10.1016/j.insmatheco.2017.01.007

Clingman, M., Burkhalter, K. \& Chaplain, C. (2014), "Money's Worth Ratios under the OASDI Program for Hypothetical Workers." Office of the Actuary, Social Security Administration, Actuarial Note, 2014.7.

EC (2011), "Guidelines on the application of Council Directive 2004/113/EC to insurance, in the light of the judgment of the Court of Justice of the European Union case C-236/09 (TestAchats)".

European Court of Justice (2011), Verdict of March 1, 2011. File Reference C-236/09, Brussels.

Elveren, A. Y. (2008), Assessing gender inequality in the Turkish pension system, International Social Security Review 61(2), 39-58.

Finkelstein, A., Poterba, J. \& Rothschild, C. (2009), Redistribution by insurance market regulation: Analyzing a ban on gender-based retirement annuities, Journal of Financial Economics 91, $38-58$

Fong, J.H., Shao, A.W. \& Sherris, M. (2015), Multistate Actuarial Models of Functional Disability, North American Actuarial Journal, 19(1), 41-59.

Fong, J.H., Sherris, M. \& Yap, J. (2017), Forecasting disability: application of a frailty model, Scandinavian Actuarial Joumal, 17(2), 125-147.

Forder, J. \& Fernández, J.L. (2011), What works abroad? Evaluating the funding of long-term care: International perspectives. Report commissioned by Bupa Care Services, PSSRU Discussion Paper 2794, Canterbury: PSSRU.

Gustman, A.L., Steinmeier, T.L. \& Tabatabai, N. (2013), Redistribution under the Social Security benefit formula at the individual and household levels, 1992 and 2004, Journal of Pension Economics and Finance, 12(1), 1-27

Haberman, S. \& Pitacco, E. (1999), Actuarial models for disability insurance. Chapman and Hall. London.

Hariyanto, E., Dickson, D. \& Pitt, G.W. (2014a), Estimation of Disability Transition Probabilities in Australia I: Preliminary. Annals of Actuarial Science, 8(1), 131-155.

Hariyanto, E., Dickson, D. \& Pitt, G.W. (2014b), Estimation of Disability Transition Probabilities in Australia II: Implementation. Annals of Actuarial Science, 8(1), 156-175.

Helwig, D. (2014), The Actuarial Argument for Gender-Distinct LTC Rates, Long-Term Care News, Society of Actuaries, April, Issue-35. 
Imai, K. \& Soneji, S. (2007), On the estimation of disability-free life expectancy. Journal of the American Statistical Association, 102 (480): 1199-211.

James, E. (2012), "Gender in the (Nonfinancial) Defined Contribution World: Issues and Options" In Gender, Politics, and Financial Stability, chap. 10, vol. 2 of Nonfinancial Defined Contribution Pension Schemes in a Changing Pension World, ed. Robert Holzmann, Edward Palmer, and David A. Robalino. Washington, DC: World Bank and Swedish Social Insurance Agency.

James, E., Cox-Edwards, A. \& Wang, R. (2003), The gender impact of pension reform, Journal of Pension Economics and Finance, 2(2), 181-219.

Luy, M. \& Minagwa, Y. (2014), Gender gaps-Life expectancy and proportion of life in poor health. Health Reports 25(12), 12-19.

Mayhew, L. \& Smith, D. (2014), Gender Convergence in Human Survival and the Postponement of Death, North American Actuarial Journal, 18(1), 194-216.

Mazzaferro, C., Morciano, M. \& Savegnago, M. (2012), Differential mortality and redistribution in the Italian notional defined contribution system, Journal of Pension Economics and Finance, 11(4), $500-530$.

Mesa-Lago, C. \& Bertranou, F. (2016), Pension reforms in Chile and social security principles, 1981-2015, International Social Security Review 69(1), 25-45.

Nusselder, W., Looman, C., Van Oyen, H., Robine, JM. \& Jagger, C (2010), Gender differences in health of EU10 and EU15 populations: the double burden of EU10 men. European Journal of Ageing 7:219-227

OECD (2015), Pensions at a Glance 2015: OECD and G20 indicators, OECD Publishing, Paris. http://dx.doi.org/10.1787/pension glance-2015-en

Ornelas A., Guillén, M. \& Alcañiz M. (2013), Implications of Unisex Assumptions in the Analysis of Longevity for Insurance Portfolios. In: Fernández-Izquierdo M.Á., Muñoz-Torres M.J., León R. (eds) Modeling and Simulation in Engineering, Economics, and Management. Lecture Notes in Business Information Processing, vol 145. Springer, Berlin, Heidelberg

Oxera (2011a), Gender and insurance: unintended consequences of unisex insurance pricing, Oxford: Oxera Consulting.

Oxera (2011b), Gender and insurance: impact on EU consumers of a ban on the use of gender Oxford: Oxera Consulting.

Oxera (2011c), The impact of a ban on the use of gender in insurance, Oxera Consulting.

Pitacco, E. (2014), Health Insurance. Basic actuarial models. EAA Series. Springer.

Pitacco, E. (2002), LTC insurance in Italy. Paper presented at the XXVII ICA - Cancun, 2002 Health Seminar on Critical Issues in Managing Long-Term Care Insurance.

Pla-Porcel, J., Ventura-Marco, M. \& Vidal-Meliá, C. (2016a), Life Care Annuities (LCA) Embedded in a Notional Defined Contribution (NDC) Framework, Astin Bulletin, 46(2), 331 363.

Pla-Porcel, J., Ventura-Marco, M. \& Vidal-Meliá, C. (2016b), Converting retirement benefit into a life care annuity with graded benefits, Scandinavian Actuarial Journal, DOI: 10.1080/03461238.2016.1258370. Published online: 21 Nov 2016.

Robinson, J. (1996), A Long-Term Care Status Transition Model. In Proceedings of The Old-Age Crisis-Actuarial Opportunities: The 1996 Bowles Symposium, pp.72-79, Georgia State University, Atlanta. 
Samuel, C. (2014), EU Gender-Neutral Pricing. A Marketing Response, paper presented at Society of Actuaries, general meeting and exhibit. Oct 26-29 Orlando, Florida

Sass, J. \& Seifried, F.T. (2014), Insurance markets and unisex tariffs: is the European Court of Justice improving or destroying welfare? Scandinavian Actuarial Journal, 14(3), 228-254.

Schmeiser, H., Störmer, T. \& Wagner, J. (2014), Unisex Insurance Pricing: Consumers' Perception and Market Implications, The Geneva Papers on Risk and Insurance, 39(2): 322-350.

Schokkaert, E. \& Van Parijs, P. (2003) Debate on social justice and pension reform. Journal of European Social Policy, 13(3), 245-79.

Spillman, B., Murtaugh, C. \& Warshawsky, M. (2003), Policy implications of an annuity approach to integrating long-term care financing and retirement income, Journal of Aging and Health, 15(1), 45-73.

Ståhlberg, A. C., Cohen, M, Kruse, A. \& Sunden, A. (2006), "Pensions reforms and gender: The case of Sweden", in Gilbert Neil, Parent Antoine (eds.), Gender and Social Security Reform: What's Fair for Women? New Brunswick, N.J., Transaction Publishers, 239 p.

Sullivan, D.F., (1971), A single index of mortality and morbidity. HSMHA Health Reports 86(4), $57-74$.

Tanaka, S. (2016), A Proposal for Redesigning Social Security: Long-Term Care Pension. The Geneva Papers on Risk and Insurance Issues and Practice, 41(1), 98-117.

The Council of the European Communities (CEC) (1979), Council Directive 79/7/EEC of 19 December 1978 on the progressive implementation of the principle of equal treatment for men and women in matters of social security, O.J. L 6, 10 January 1979, 24-25. http://data.europa.eu/eli/dir/1979/7/oj

The Council of the European Communities (CEC) (2004), Council Directive 2004/113/EC of 13 December 2004 implementing the principle of equal treatment between men and women in the access to and supply of goods and services, O.J. L 373, 21 December 2004, 37-43. http://data.europa.eu/eli/dir/2004/113/oi

The Swedish Pension System. Orange Annual Report 2015. (TSPS) (2016), Ed. Ole Settergren and Karl Birkholz, Swedish Pensions Agency (Pensionsmyndigheten), Stockholm. http://www.pensionsmyndigheten.se/Publications en.html

Thiery, Y. \& Van Schoubroeck, C. (2006), Fairness and equality in insurance classification, The Geneva Papers 31, 190-211

Villegas, A. M. \& Haberman, S. (2014), On the modelling and forecasting of socio-economic mortality differentials: an application to deprivation and mortality in England, North American Actuarial Journal 18(1): 168-193.

Warshawsky, M. (1988), Private Annuity Markets in the United States: 1919-1984. The Journal of Risk and Insurance, 55(3), 518-528

Warshawsky, M.J. (2012), Retirement Income: Risks and Strategies. Cambridge, MA: MIT Press.

Whitehouse, E. \& Zaidi, A. (2008), "Socio-Economic Differences in Mortality: Implications for Pensions Policy.” OECD Social, Employment and Migration Working Papers, No. 71, OECD Publishing, Paris.

\section{Appendix 1: The unisex actuarial factor}

Under the actuarial equivalence principle, the present value of an LCA with graded benefits should be equal to the accumulated capital from contributions made by the contributor, valued at the age they become a beneficiary. If the initial payment to be received by the annuitant is set 
equal to 1 , then the accrued contributory rights and the pure premium are equivalent to the actuarial factor, $A F_{x_{e}}^{L C A(a, n)}$.

If the actuarial factor is built from unisex morbidity and mortality tables, it will not be possible to reach actuarial fairness for both genders given that by mixing probabilities the resulting factor is:

$$
\operatorname{Min}\left\{A F_{\left(x_{e}, m\right)}^{L C A(a, n)}, A F_{\left(x_{e}, f\right)}^{L C A(a, n)}\right\}<A F_{\left(x_{e}, u\right)}^{L C A(a, n)} \leq \operatorname{Max}\left\{A F_{\left(x_{e}, m\right)}^{L C A(a, n)}, A F_{\left(x_{e}, f\right)}^{L C A(a, n)}\right\}
$$

or

$$
\operatorname{Min}\left\{A F_{\left(x_{e}, m\right)}^{L C A(a, n)}, A F_{\left(x_{e}, f\right)}^{L C A(r, n)}\right\} \leq A F_{\left(x_{e}, u\right)}^{L C A(a, n)}<\operatorname{Max}\left\{A F_{\left(x_{e}, m\right)}^{L C A(a, n)}, A F_{\left(x_{e}, f\right)}^{L C A(a, n)}\right\}
$$

There are several alternatives for computing the unisex actuarial factor, $A F_{\left(x_{e}, f\right)}^{L C A(a, n)}$, and the level of gender redistribution will be different for each of them.

We briefly develop three, although alternatives 2 and 3 are equivalent. The main assumptions are that the males and females are the same age and in the same health state when they become entitled to receive benefits, their accrued contributory rights are identical and we have all the necessary information on gender mortality, morbidity and transition probabilities.

1) Linear convex combination of the one-year transition probabilities for both genders:

$$
\begin{aligned}
& p_{\left(x_{e}+k, u\right)}^{a a}=w \cdot p_{\left(x_{e}+k, m\right)}^{a a}+(1-w) \cdot p_{\left(x_{e}+k, f\right)}^{a a} \\
& p_{\left(x_{e}+k, u\right)}^{a d_{j}}=w \cdot p_{\left(x_{e}+k, m\right)}^{a d_{j}}+(1-w) \cdot p_{\left(x_{e}+k, f\right)}^{a d_{j}} \\
& p_{\left(x_{e}+k, u\right)}^{d_{i} d_{j}}=w \cdot p_{\left(x_{e}+k, m\right)}^{d_{i} d_{j}}+(1-w) \cdot p_{\left(x_{e}+k, f\right)}^{d_{i} d_{j}}
\end{aligned}
$$

where in practice $w=\frac{l_{e}^{m}}{l_{e}^{m}+l_{e}^{f}} \in[0,1]$ is the males' proportion in the cohort of beneficiaries, with $(1-w)$ being the females' proportion in the initial collective ${ }^{19}$.

In fact the one-year transition probabilities for each gender and for ages and health states have a multinomial distribution. The main implication is that the multiyear transition probabilities linked to the unisex actuarial factor are an outcome of an iterative process of combining probabilities from multinomial distributions. Given that these distributions differ by age and health state, it is not possible to get a closed form expression, so the resulting actuarial rates depend on $w$,

$$
\ddot{a}_{\left(x_{e}, u, w\right)}^{a \alpha},\left\{{ }^{\xi_{a j}} A_{\left(x_{e}, u, w\right)}^{a d_{j} \alpha}\right\}_{j \in\{1,2, \cdots, n\}}, A F_{\left(x_{e}, u, w\right)}^{L C A(a, n)}
$$

this relation being complex and non-linear. In short, the unisex actuarial factor is not actuarially fair from a cohort point of view:

\footnotetext{
${ }^{19}$ This is called the "unisex actuarial principle" by Chen \& Vigna (2017).
} 


$$
A F_{\left(x_{e}, u, w\right)}^{L C A(a, n)} \neq w \cdot A F_{\left(x_{e}, m\right)}^{L C A(a, n)}+(1-w) \cdot A F_{\left(x_{e}, f\right)}^{L C A(a, n)}
$$

If the actuarial equivalence principle at cohort level had to be met taking into account [10.], then we would need to solve the following implicit equation with regard to $w^{*} \in[0,1]$ :

$$
\left(l_{e}^{m}+l_{e}^{f}\right) \cdot A F_{\left(x_{e}, u, w^{*}\right)}^{L C A(a, n)}=l_{e}^{m} \cdot A F_{\left(x_{e}, m\right)}^{L C A(a, n)}+l_{e}^{f} \cdot A F_{\left(x_{e}, f\right)}^{L C A(a, n)}
$$

The solution will depend on the main elements of the actuarial factor, i.e. the indexation rate, $\alpha$, the technical interest rate, $G$, and the uplifts scale, $\xi$. Given the complexity of the task, an alternative way to compute $w^{*} \in[0,1]$ could be to minimize the weighted absolute deviations of the gender actuarial factors $\left\{A F_{\left(x_{e}, m\right)}^{L C A(a, n)}, A F_{\left(x_{e}, f\right)}^{L C A(a, n)}\right\}$ with respect to the unisex factor $A F_{\left(x_{e}, u, w^{*}\right)}^{L C A(a, n)}$.

2) Linear convex combination of the multiyear transition probabilities for both genders:

$$
\begin{aligned}
& { }_{k} p_{\left(x_{e}, u\right)}^{a a}=w \cdot{ }_{k} p_{\left(x_{e}, g\right)}^{a a}+(1-w) \cdot{ }_{k} p_{\left(x_{e}, f\right)}^{a a} \\
& { }_{k} p_{\left(x_{e}, u\right)}^{a d_{j}}=w \cdot{ }_{k} p_{\left(x_{e}, m\right)}^{a d_{j}}+(1-w) \cdot{ }_{k} p_{\left(x_{e}, f\right)}^{a d_{j}} \\
& { }_{k} p_{\left(x_{e}, u\right)}^{d_{i} d_{j}}=w \cdot{ }_{k} p_{\left(x_{e}, m\right)}^{d_{i} d_{j}}+(1-w) \cdot{ }_{k} p_{\left(x_{e}, f\right)}^{d_{i} d_{j}}
\end{aligned}
$$

In this case, if the probabilities to be combined are linked to actuarial valuations defined for completed intervals $\left[x_{e}, x_{e}+k\right]$, then the unisex actuarial factor turns out to be a linear convex combination of the actuarial factors for both genders:

$$
A F_{\left(x_{e}, u, w\right)}^{L C A(a, n)}=w \cdot A F_{\left(x_{e}, m\right)}^{L C A(a, n)}+(1-w) \cdot A F_{\left(x_{e}, f\right)}^{L C A(a, n)}
$$

because this unisex factor is the weighted sum of the factors corresponding to each of the possible health states, which are a linear convex combination of the gender actuarial factors:

$$
\begin{gathered}
\ddot{a}_{\left(x_{e}, u, w\right)}^{\alpha \alpha}=w \cdot \ddot{a}_{\left(x_{e}, m\right)}^{r \alpha}+(1-w) \cdot \ddot{a}_{\left(x_{e}, f\right)}^{a \alpha} \\
\xi^{a j} A_{\left(x_{e}, g\right)}^{a d_{j} \alpha}=w \cdot{ }^{\xi a j} A_{\left(x_{e}, m\right)}^{a d_{j} \alpha}+(1-w) \cdot{ }^{\xi a j} A_{\left(x_{e}, f\right)}^{a d_{j} \alpha}
\end{gathered}
$$

Therefore, with $w$ being the males' proportion in the cohort of initial beneficiaries and (1-w) the females' proportion, [15.] satisfies the unisex fairness principle at a collective level.

3) Linear convex combination of the gender actuarial factors.

$$
A F_{\left(x_{e}, u\right)}^{L C A(a, n)}=w \cdot A F_{\left(x_{e}, m\right)}^{L C A(a, n)}+(1-w) \cdot A F_{\left(x_{e}, f\right)}^{L C A(a, n)}
$$

In practice, this approach is equivalent to the previous one. 
Appendix 2: Life expectancy in years at ages 61 and 70 and percentage of total life expectancy likely to be spent in each health state.

Data are available upon request to the authors.

Appendix 3: Redistribution: detailed results by gender, age and health state under several assumptions.

Detailed results are available upon request to the authors. 